\title{
O TRABALHO IMATERIAL EM DISCUSSÃO: teoria e política
}

\author{
INTRODUÇÃO
}

Henrique Amorim*

Nas últimas duas décadas, o trabalho imaterial foi objeto de muitas análises nas Ciências Sociais. Grosso modo, as considerações sobre o tema foram influenciadas por duas grandes transformações nas sociedades contemporâneas. De um lado, o fim da bipolaridade político-econômica entre Estados Unidos e União Soviética e, de outro, as transformações, tais como a robótica, a microeletrônica e as novas formas de gestão empresarial da mais recente reestruturação produtiva caracterizaram os pilares empíricos de redimensionamento das análises sobre a produção e o trabalho.

A diminuição de postos de trabalho nas indústrias de países de economia avançada e, ao mesmo tempo, o aumento das ocupações profissionais que passam a exigir maior intervenção intelectual pareciam indicar a tendência de eliminação do trabalho imediato e a predominância de trabalhos mediatos, isto é, atividades predominantemen-

* Doutor em Ciências Sociais. Professor de Sociologia do Departamento de Ciências Sociais e do Programa de Pósgraduação em Ciências Sociais da Universidade Federal de São Paulo (UNIFESP/Guarulhos).

Av. Monteiro Lobato, 679. Bairro Macedo. Cep: 07112-000. Guarulhos-São Paulo-Brasil. henriqueamorim@hotmail.com te intelectualizadas ou imateriais.

Em fins da década de 1970, um conjunto de teses procurou explicar como a nova constituição da produção não mais poderia ser analisada pelo marxismo, já que a sociabilidade não era mais determinada pelo trabalho. Nos anos 1980, essa perspectiva se radicaliza com a expansão do setor de serviços e do trabalho imaterial e o corpo teórico da análise marxiana é questionado.

O trabalho imaterial foi, a partir de então, um objeto de estudos recorrente no debate sociológico, político e econômico contemporâneo, na medida em que trazia consigo novas formas de exploração e de luta política ainda não mapeadas e não problematizadas teoricamente. Nesse contexto, pelo menos duas grandes perspectivas analíticas, com muitas nuanças internas, se digladiaram. De um lado, vislumbrou-se o esgotamento do capitalismo como uma sociedade organizada em torno do trabalho e da indústria e, por consequência, das utopias revolucionárias. De outro, houve uma retomada de Marx para qualificar as transformações produtivas e gerenciais como expressão de uma nova fase do processo de valorização e acumulação capitalista. 
Estruturadas por diferentes horizontes teóricos e políticos, essas perspectivas de leitura do trabalho imaterial tiveram como referência inicial os Grundrisse de Karl Marx, texto escrito entre 1857-1858. No entanto, a apropriação do conceito de trabalho imaterial, de incorporação da tecnologia e ciência à produção, da redução do tempo de trabalho necessário e de ampliação do tempo livre, da constituição do general intellect e do indivíduo social desenvolvida por Marx nesse texto foi realizada de diferentes formas no debate sobre o trabalho imaterial.

Assim, Marx dos Grundrisse foi base, ao mesmo tempo, tanto para explicar a transição do capitalismo industrial para um suposto capitalismo cognitivo como para demonstrar como a exploração do trabalho não se limitaria à exploração do trabalho na fábrica e, portanto, que a valorização do capital pode ser realizada tanto sob o signo do trabalho material quanto do trabalho imaterial.

Em linhas gerais, as questões colocadas pela discussão sobre o trabalho imaterial giraram em torno de qual seria o sentido da produção imaterial? O trabalho imaterial indica um novo padrão de organização de sociabilidade ou aprofunda o padrão capitalista atual? Ele é expressão de uma nova lógica social de sociedades pós-industriais ou recompõe e conserva a base estrutural das sociedades capitalistas características dos séculos XIX e XX?

Buscando dar respostas, pistas e possíveis diagnósticos para essas questões, o dossiê, $O$ trabalho imaterial em discussão: teoria e política traz diversificadas abordagens, compilando autores e teses com perspectivas analíticas distintas sobre o trabalho imaterial e também sobre temas fundamentalmente atuais. Assim, questões que cercam a relação entre o tempo de trabalho necessário e o tempo livre, o trabalho produtivo, o improdutivo e os serviços, o trabalho intelectual e o trabalho manual, o conhecimento, o saber e as qualificações profissionais, as classes sociais, a valorização do capital e a renda, entre tantas outras, são desenvolvidas nos artigos que compõem esse dossiê.

Com a expectativa de se caracterizar como uma importante referência em estudos e pesqui- sas que procuram tanto se introduzir na discussão quanto ambicionam uma leitura mais detalhada e profunda do tema, o dossiê traz oito artigos que, além de se fundamentarem em elementos teóricos e empíricos, indicam a complexidade do tema e, portanto, a necessidade de seu desenvolvimento intelectual.

O artigo que abre nosso dossiê é o de Ursula Huws, "Vida, Trabalho e Valor no Século 21: desfazendo o nó". Nesse texto, Huws analisa as atuais formas de trabalho "imaterial" ou "digital", com o objetivo de indicar quais seriam os espaços ou lugares nos quais a produção de valor se realiza. Com base em um esquema analítico que divide o trabalho em "trabalho remunerado" e "trabalho não remunerado" e os relaciona às formas do "trabalho reprodutivo" e do "trabalho diretamente produtivo", sustenta que, com base nas teses de Marx, é possível definir o que é uma mercadoria, identificar os locais nos quais são produzidas (materiais e imateriais) e definir a classe trabalhadora global imersa nessa produção.

Fundamentando sua análise em uma crítica às teses que indicam ser o trabalho imaterial a nova força produtiva do capitalismo contemporâneo, Henrique Amorim, em seu artigo, "As teorias do trabalho imaterial: uma reflexão crítica a partir de Marx", retoma algumas das obras centrais de Marx na tentativa de descrever as diferenças entre as formulações desse autor acerca dos conceitos de trabalho, valor e classe social e a interpretação desses conceitos realizada pela chamada "economia do conhecimento". Identifica, assim, um reducionismo analítico, exposto, sobretudo, nas teses que restringem os conceitos marxianos à produção fabril.

No terceiro artigo, "O trabalho imaterial no ciclo de material do capital e a determinação das classes sociais no capitalismo contemporâneo", Adrián Sotelo Valencia relaciona o trabalho imaterial aos problemas atuais das sociedades contemporâneas e, em especial, às crises ocorridas no século XXI. Para isso, parte da tese segundo a qual o trabalho intelectual é parte da força de trabalho e é pensado como uma forma social do trabalhador coletivo, utilizado pelo capital como meio de pro- 
dução do valor. O autor aponta para uma "articulação virtuosa" entre o trabalho material e o trabalho imaterial que opera dialeticamente na produção de informação, ciência e tecnologia.

Com o título "Subsunção do trabalho imaterial ao capital”, Eleutério F. S. Prado e José Paulo Guedes Pinto trazem elementos conceituais significativos para a reflexão sobre como o trabalho imaterial pode ser considerado expressão tendencial da indústria pós-taylorista. Ao diagnosticar diferenças estruturais entre a produção taylorista e a pós-taylorista, os autores desenvolvem a tese de que estaria em curso uma transformação do sistema capitalista que caracterizaria o surgimento de um novo modo de produção. Com a substituição de regras externas e arbitrárias de controle do trabalhador pela garantia de que ele "atue como um colaborador aparentemente voluntário", configurar-se-ia a transformação da grande indústria na pós-grande indústria, na qual o trabalho imaterial exerce protagonismo.

Com o objetivo de discutir a produção de valor e mais-valia no setor de serviços, Sadi Dal Rosso, em seu artigo "Teoria do valor e trabalho produtivo no setor de serviços", percorre as determinações da relação entre o que é ou não produtivo em cada setor da produção capitalista. Faz, assim, o exame dos setores primário, secundário e terciário, procurando diagnosticar, para cada um deles, em que medida se produz valor e mais-valia. Não obstante, seu foco central visa ao estabelecimento de distinções, dentro do setor de serviços, entre o trabalho produtivo e o trabalho improdutivo, ressaltando a atualidade da teoria do valor-trabalho de Marx para qualificar essas relações sociais.

Benedito Rodrigues de Moraes Neto, no texto: "Emprego e trabalho no Século XXI: revisitando Keynes e Marx", como o subtítulo sugere, retoma Keynes e Marx para dar pistas sobre como analisar as formas de utilização da força de trabalho nos últimos anos. Partindo das noções de "trabalho desprovido de conteúdo" e "trabalho atividade", o artigo de Moraes Neto objetiva ilustrar, com base em fontes empíricas, as possibilidades de efetivação social do "trabalho livre e emancipado", sobretu- do tendo como referência a relação entre o desenvolvimento das forças produtivas e as relações de produção capitalistas no quadro da produção taylorista-fordista e as atuais formas de organização do trabalho.

Retomando as principais teses que constituem o edifício teórico de André Gorz, Josué Pereira da Silva, com o texto "Tempo de trabalho e imaterialidade na teoria social de André Gorz", procura discutir a perspectiva de Gorz em relação ao trabalho imaterial e identifica mudanças na estrutura de produção do capitalismo contemporâneo, ao indicar que o trabalho imaterial, baseado na produção e no conhecimento, não poderia ser medido em unidades de tempo. Essa transformação implicaria, para Silva, a substituição do trabalho pelo conhecimento como principal força produtiva. Assim, o modelo baseado no tripé conceitual "trabalho, valor e capital" seria substituído pelo tripé "conhecimento, valor e capital", o que abriria novas formas de luta política fora do universo do trabalho.

Por fim, o dossiê sobre o trabalho imaterial se encerra com o texto, "Valor, renda e 'imaterialidade' no capitalismo contemporâneo”, de Sávio Cavalcante. A porta de entrada para a discussão do trabalho imaterial de Cavalcante se dá pela articulação entre os conceitos de valor e renda. Analisa, assim, as teses da teoria do trabalho imaterial, mostrando como o capitalismo, na atualidade, se fundamenta no caráter rentista da economia, ocasionado por uma relativa autonomização do capital em relação ao trabalho vivo.

O século XXI, nesses primeiros anos de existência, radicalizou as formas de exploração do trabalho. Tanto as atividades profissionais ligadas à produção de mercadorias materiais quanto aquelas que produzem bens imateriais passaram por um processo de radicalização de suas formas de controle gerencial e de intensificação do trabalho. Nesse quadro, de degradação da classe trabalhadora, o dossiê "Trabalho imaterial em discussão: teoria e política" procura apresentar algumas alternativas, propostas e, sobretudo, um exame do trabalho imaterial no âmbito da produção capitalista. 
Gostaria, por fim, de agradecer a Dadá Marques pela presteza e atenção durante o processo de organização do dossiê, a Sávio Cavalcante pela tradução do texto de Ursula Huws, a todos os pareceristas que gentilmente realizaram o trabalho de avaliação dos artigos, aos autores que pronta- mente aceitaram participar dessa empreitada e a toda a editoria do Caderno $\mathrm{CRH}$, que nos conferiu a oportunidade de organizar o dossiê que aqui se apresenta.

Recebido para publicação em 15 de dezembro de 2013 Aceito em 20 de dezembro de 2013

Henrique Amorim - Doutor em Ciências Sociais. Professor de Sociologia do Programa de Pós-Graduação em Ciências Sociais da Universidade Federal de São Paulo (UNIFESP-Campus Guarulhos). Pós-doutor no Departamento de Sociologia (IFCH/UNICAMP) e na École des Hautes Études en Sciences Sociales. Coordenador do projeto de pesquisa, financiado pela FAPESP e pelo CNPq: Classes Sociais e Valor na Teoria Social Contemporânea. Atua na área de Sociologia, com ênfase em sociologia do trabalho e teoria social, trabalhando principalmente com os seguintes temas: trabalho, movimentos e classes sociais, produção, processos de trabalho e valor. Além de artigos nesses temas, é autor dos livros: Valor-trabalho e imaterialidade da produção nas sociedades contemporâneas, publicado pelo CLACSO em 2012; Trabalho Imaterial: Marx e o debate contemporâneo, publicado pela Annablume/FAPESP em 2009; e Teoria Social e Reducionismo Analítico: para uma crítica ao debate sobre a centralidade do trabalho, publicado pela EDUCS em 2006. 